\title{
Energy Conservation in Blast Furnace Stoves by Improving Efficiency of Combustion Air Fan Through Variable Frequency Drives
}

\author{
Dr.L. Ashok Kumar ${ }^{1}$, R. Divya ${ }^{2}$, J. Devakumar ${ }^{3}$ \\ \{lak.eee@psgtech.ac.in ${ }^{1}$,divyaravi003@gmail.com ${ }^{2}$, lakpsg@gmail.com ${ }^{3}$ \} \\ EEE Department, PSG College of Technology, Coimbatore, India ${ }^{1,2}$, Manager, JSW Steels Private Ltd \\ Salem, India ${ }^{2}$
}

\begin{abstract}
Energy saving is one of the important factors to be considered in case of the blast furnace, In this proposed system provides effectual energy conservation of the blast furnace stoves by using variable frequency drives. This system also gives well efficiency of the combustion air fan with help of VHD drive. This proposed architecture is simulated, and output is taken according to the algorithm developed and parameter were tested and validated it has been demonstrated by using LABVIEW software model. LABVIEW Model for the simulation is also proposed for validation and testing.
\end{abstract}

Keywords: Labview, Blast Furnace, Energy Saving.

\section{Introduction}

This The concept of improving energy efficiency of STOVES by reducing the energy consumption of Combustion air fan using Variable Frequency Drives (VFD) is proposed in this paper. The combustion air fan is driven by the 3 phase induction motor. The speed of which is controlled by varying the frequency which is accomplished by using the VFD DRIVE. By controlling the speed of the motor the amount of air that is suctioned into the Stoves can be manipulated. Presently by adjusting the open position of the inlet damper in auto mode the flow of the air into the stoves are controlled. In this method when the pressure drops below 750mmWC the inlet damper valve is opened partially in accordance with the pressure. Drawbacks associated with this method is that motor is not used effectively as the flow is controlled by the partial opening or closing of the valve, the response time is also less in this system and reliability is also reduced. In this system the speed of the fan which is driven by induction motor is controlled by changing the RPM of the motor which in turn controlled by changing the frequency by using VFD. LABVIEW Model for the simulation is also proposed for validation. 


\section{Literature Review}

The composition of the reducing gases is explained after compression of the blast-furnace gases. System for recycling the blast-furnace gas and removing the $\mathrm{CO} 2$ is considered [1]. The economic and energy benefits obtained by the injection of hot reducing gases are explained. The energy efficiency of hot-metal production increases by $40 \%$ [2]. Selection of gain factor for the discrete proportional-integral-derivative (PID) controller which is required logical approach and it could be presented in this paper. In this paper reviewed mainly for the nonlinear multiple-input-multiple-output (MIMO) based robustly control plant with help of gain attained PID controller. It is commonly equal to second-order controller canonical form similar to robot dynamics[3]. This paper is mainly used to determine the discrete type of PID controller which is equivalent to the time delay control (TDC) and uncertainty based robust control. [10]. In this proposed architecture model is developed from the open-loop data which is used as reference model to evaluate a closed-loop system performance detection approach. A laboratory-based test setup was developed for the closed-loop system field which is given reference [12]. A new control system model is suggested to attain the heating curves which represent the production of energy conservation. Tracking error was minimized in this proposed Model Predictive Control (MPC) method which to the reference of the system, while fulfilling process constraints [13]. This paper focussing on reducing the Load-shifting while demand increases particularly for electricity during peak time intervals [15]. In this paper primarily reviewed on the analytical model for the non-parametric data envelopment analysis (DEA) in order to calculate energy efficiency (EE) of 34 coal-fired power units which is established in China. Input-oriented CCR (Charnes, Cooper and Rhodes) model is used for EE analysis [18].Two effective index model could be analyzed for two important things which could be generalized EE and special EE. These two methods are mainly focusing on power consumption which is calculated based on four input parameters: coal utilization, oil consumption, water usage and auxiliary power spending by power units [20]. The need for demand side management (DSM) and the improvement of existing DSM projects are highlighted. This leads to the problem statement and objectives of this study. An overview of this document is also presented [22]. There is a need of studying and identify the problems and some possibilities of Load shifting in the conveyor systems at South African coalmines. Load shifting could be simulated and theses Simulation results are used to forecast the impress on manufacturing during performance testing validation and installation of the innovative load shifting model [23]. In this paper, an energy conservation scheme was developed on the cold blast air system of a blast furnace. A new methodology was implemented for problem identification in the proposed model which could be studied in this paper [24]. In order to achieve the $1.3 \mathrm{MW}$ energy conservation by reducing the pressure around $20 \mathrm{KPa}$ for cold blast supply pressure unit. Due to this cost savings add to the reduction in the functioning cost of an iron production plant [25].

\section{3. proposed system}


The Block Diagram has been presented for the CA Fan unit were the Motor and the Fan are coupled together by means of the shaft, the input to the motor will be the power and the output will be the airthat is being pumped out.

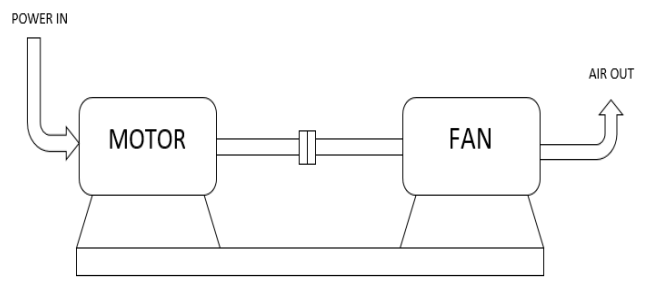

Fig 1.1 CA FAN Unit

The Schematic diagram for the air suctioned into the stoves is presented in the Fig 1.2. By controlling the speed of the motor the amount of air that is suctioned into the Stoves can be manipulated. Presently by adjusting the open position of the inlet damper in auto mode the flow of the air into the stoves are controlled

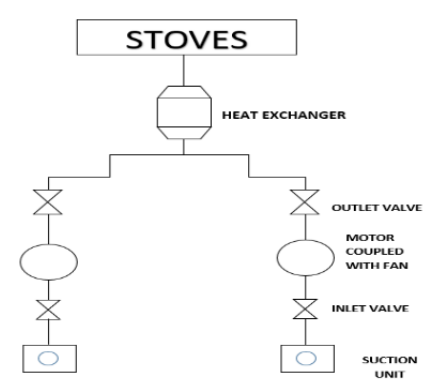

Fig 1.2 Schematic Diagram for The Stoves

\section{Energy saving concept and fan curve}

Energy auditing is a main key role of any production plant industries so it is necseeary to optimize the energy and reducing the energy wastage. There is an proper design consideration of fan,pump and blower application unit which is predomiantely affect the energy wastage When we use conventional motor control system uses the many control application for the production industries such that the flow of air,gases and liquid is continusoly regulated by using damper /throttle control with help of AC motor at full speed.. finally it concludes that the of process significant energy is lost due to the imporper design of damper/throttle [4]. This losses of energy could be as high as 25 to $30 \%$ of motor rating. This system needs highly reilable (v/f) variable speed drive leads to control the speed of the blower, which will automatically control the flow of air. Hence it can eliminate the required of damper. 


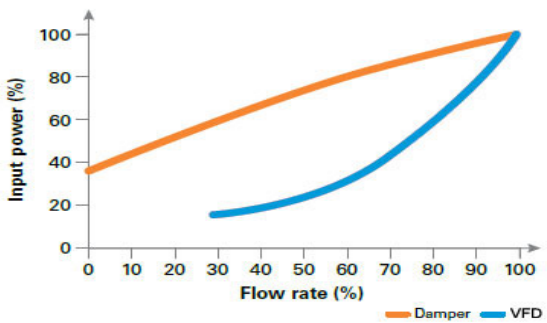

Fig 1.3 Graph of energy saving concept

This graph clearly presents that when we make use of the Damper for minimum flow rate we require more input Power compared to that of the VFD Drive,hence usage of Damper is not much efficient when compared to that of the VFD Drive.At maximum Flow rate both the Damper and the VFD Drive consumes more amount of input Power thus the valve should not be kept completely open as the amount of energy conserved decrreases.

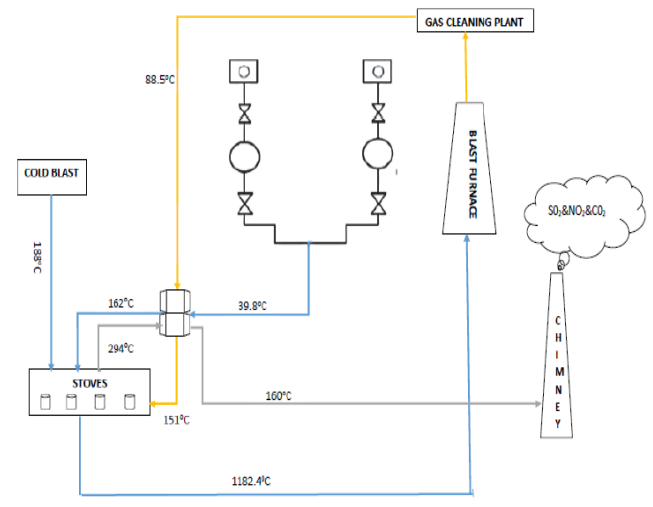

Fig 1.4 Schematic Block of VFD

Overall schematic block diagram of the VFD Drive implemented in the plant is presented and the temperature range taken at a particular time for the Blast Furnace,Stoves, Heat Exchanger are noted down.

Table 1.1 Parameters

\begin{tabular}{|l|l|}
\hline PARAMETERS & RATING \\
\hline Motor Power Rating & $316000 \mathrm{Kw}$ \\
\hline Rated rpm & $1480 \mathrm{rpm}$ \\
\hline Rated Air Flow & 53000 \\
\hline
\end{tabular}




\begin{tabular}{|l|l|}
\hline Pole & 4 \\
\hline For Energy & $24 \mathrm{hrs}$ \\
\hline
\end{tabular}

Table 2.2. Parameters

\begin{tabular}{|l|l|}
\hline DATA & SYMBOL \\
\hline Fraction of air flow & Fo \\
\hline Rated air flow & $\mathrm{Ro}$ \\
\hline Rated rpm & $\mathrm{Nr}$ \\
\hline Airflow & $\mathrm{Af}$ \\
\hline $\begin{array}{l}\text { Fraction of Total Power } \\
\text { Consumed }\end{array}$ & $\mathrm{Fp}$ \\
\hline Speed & $\mathrm{N}$ \\
\hline Percentage of Power Consumed & Po \\
\hline Power Consumed & Pc \\
\hline Motor Power Rating & $\mathrm{Mp}$ \\
\hline Power Conserved & Pci \\
\hline Percentage of Power & Pco \\
\hline Frequency & Fr \\
\hline Pole & P \\
\hline Energy Consumed(kWh/year) & Econ \\
\hline Energy Conserved (kWh/year) & Ecov \\
\hline $\begin{array}{l}\text { Percentage } \\
\text { Conserved }\end{array}$ & Pce \\
\hline Power Conserved & Pcer \\
\hline
\end{tabular}

$$
\begin{array}{ll}
\text { Af } & =\mathrm{Fo}^{*} \mathrm{Ro} \\
\mathrm{N} & =(\mathrm{Nr} * \mathrm{Af}) /(\mathrm{Ro}) \\
\mathrm{Fp} & =(\mathrm{N} / \mathrm{Nr})^{\wedge} 3 \\
\mathrm{Po} & =[1-\mathrm{Fp}]^{*} 100 \\
\mathrm{Pc} & =\mathrm{Fp} \mathrm{Mp}^{*} \\
\mathrm{Pci}=([\mathrm{Pco} * \mathrm{Mp}] / 100) / 1000 & \mathrm{Fr} \quad=(\mathrm{N} * \mathrm{P}) / 120 \\
\mathrm{Econ} & =(\mathrm{Pce})^{*} 24 * 365 \\
\mathrm{Ecov} & =(\mathrm{Pcer}) * 24 * 365
\end{array}
$$

Table 2.3. Parameters 


\section{A. Tabulation}

\begin{tabular}{|l|l|}
\hline Data & Symbol \\
\hline Stove & S \\
\hline Power & P \\
\hline Flow1 & F1 \\
\hline Flow2 & F2 \\
\hline Total Flow & TF \\
\hline Pressure1 & P1 \\
\hline Pressure2 & P2 \\
\hline Total Pressure & TP \\
\hline Percentage Of Power & Per \\
\hline Percentage Of Flow & Fer \\
\hline
\end{tabular}

\section{a.Tabulation for the graph without using VFD Drive}

Table 2.4 tabulation for the graph without using VFD drive in the values are plotted for stoves operating without VFD drive and the corresponding flow, pressure are being noted down and the set point of Pressure maintained here is $760 \mathrm{~mm}$ WC for the stoves to operate.

Table 2.4 tabulation for the graph without using VFD drive

\begin{tabular}{|l|c|c|c|c|c|c|c|c|l|}
\hline \multicolumn{1}{|c|}{ S } & P & F1 & F2 & TF & P1 & P2 & TP & Per & \multicolumn{1}{c|}{ Fer } \\
\hline s3,S4 & 220 & 26600 & 20000 & 46600 & 736 & 736 & 742 & 61.11 & 466 \\
\hline S2,S3 & 215 & 25000 & 21887 & 47887 & 742 & 742 & 745 & 59.72 & 478.87 \\
\hline S1,S4 & 213 & 21000 & 26000 & 46000 & 750 & 750 & 748 & 59.17 & 460 \\
\hline S3 & 149 & 26000 & & 26000 & 755 & 755 & 755 & 41.39 & 260 \\
\hline S4 & 142 & & 23000 & 22000 & 758 & 758 & 758 & 39.44 & 220 \\
\hline S2 & 145 & 26000 & & 26000 & 750 & 750 & 760 & 40.28 & 260 \\
\hline
\end{tabular}

\section{b.Tabulation for the graph using VFD Drive}

The values are plotted for stoves operating with VFD drive and the corresponding flow, pressure and the amount of energy conserved for different Airflow are being noted down.

It is observed that when the amount of Speed varies the Fraction of Airflow is found to be varying and it is observed that for maximum airflow the amount of energy conserved is found to be zero[10]. Thus the VFD Drive operation attains its maximum energy conservation at the minimum air flow itself and also it requires much less power when compared to that of the Damper winding.

Table 2.5 Tabulation for the graph with VFD drive 


\begin{tabular}{|l|l|l|l|l|l|l|l|l|l|}
\hline Af & Fo & N & Fp & Po & Pce & Pc & Pci & Econ & Ecov \\
\hline 15900 & 0.3 & 444 & 0.027 & 97.3 & 8.532 & 307.468 & 14.8 & 74740 & 2693419.68 \\
\hline 21200 & 0.4 & 592 & 0.064 & 93.6 & 20.224 & 295.776 & 19.73 & 177162 & 2590997.76 \\
\hline 23850 & 0.45 & 666 & 0.091125 & 90.8875 & 28.7955 & 287.2045 & 22.20 & 252249 & 2515911.42 \\
\hline 26500 & 0.5 & 740 & 0.125 & 87.5 & 39.5 & 276.5 & 24.67 & 346020 & 2422140 \\
\hline 29150 & 0.55 & 814 & 0.166375 & 83.3625 & 52.5745 & 263.4255 & 27.13 & 460553 & 2307607.38 \\
\hline 31800 & 0.6 & 888 & 0.216 & 78.4 & 68.256 & 247.744 & 29.60 & 597923 & 2170237.44 \\
\hline 34450 & 0.65 & 962 & 0.274625 & 72.5375 & 86.7815 & 229.2185 & 32.07 & 760206 & 2007954.06 \\
\hline 37100 & 0.7 & 1036 & 0.343 & 65.7 & 108.388 & 207.612 & 34.53 & 949479 & 1818681.12 \\
\hline 39750 & 0.75 & 1110 & 0.421875 & 57.8125 & 133.3125 & 182.6875 & 37.00 & 1167818 & 1600342.5 \\
\hline 42400 & 0.8 & 1184 & 0.512 & 48.8 & 161.792 & 154.208 & 39.47 & 1417298 & 1350862.08 \\
\hline 45050 & 0.85 & 1258 & 0.614125 & 38.5875 & 194.0635 & 121.9365 & 41.93 & 1699996 & 1068163.74 \\
\hline 47700 & 0.9 & 1332 & 0.729 & 27.1 & 230.364 & 85.636 & 44.40 & 2017989 & 750171.36 \\
\hline 50350 & 0.95 & 1406 & 0.857375 & 14.2625 & 270.9305 & 45.0695 & 46.87 & 2373351 & 394808.82 \\
\hline 53000 & 1 & 1480 & 1 & 0 & 316 & 0 & 49.33 & 2768160 & 0 \\
\hline
\end{tabular}

\section{B.Graph}

Power Vs Air flow plot signifies the linear increase in the plot when it is operated using Damper Valve that is it operates without VFD Drive shown in figure 1.5

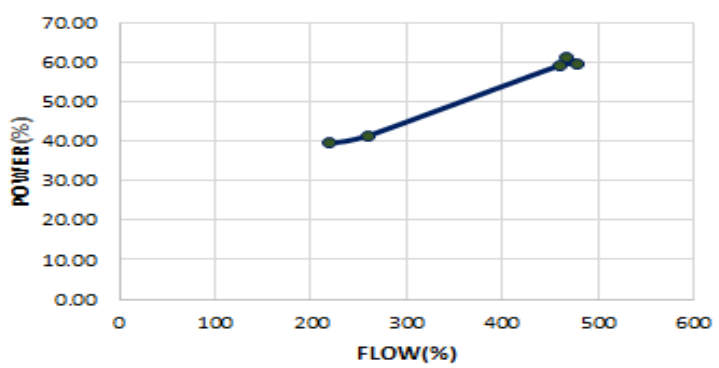

Fig 1.5 Power Vs Flow Plot

Figure 1.6 shows the plot of Flow Vs Pressure signifies that for an increase in the Pressure the Air Flow is found to be decreasing and hence it is not much efficient method.

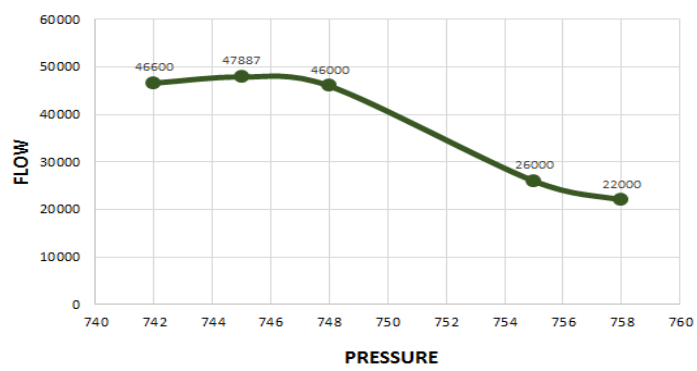

Fig 1.6 Flow Vs Pressure Plot with VFD Drive

Fig 1.7 Power Vs Flow Plot shows the Power Vs Air flow plot signifies the linear increase in the Pressure when the flow is increased when it is operated using with VFD Drive. 
This plot is verified using LabVIEW and it is much more efficient compared to the operation without VFD

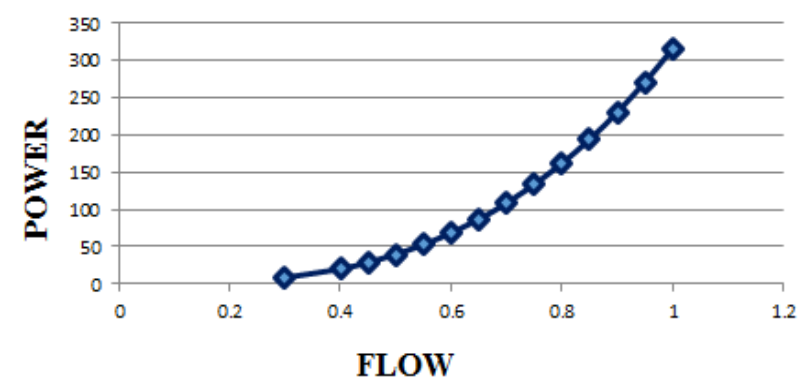

Fig 1.7 Power Vs Flow Plot

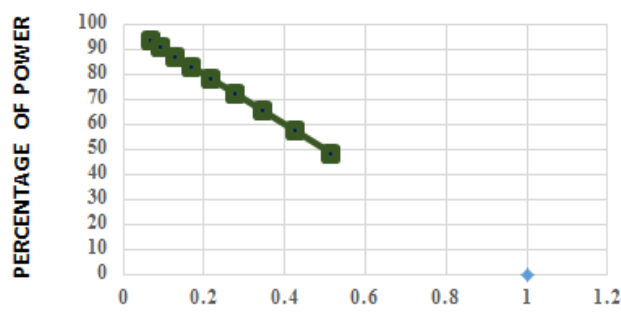

FRACTION OF POWER

Fig 1.8 Percentage of Power Vs Fraction of Power

Fig 1.8 Percentage of Power Vs Fraction of Power represents the Fraction of Power Vs Percentage of Power plot signifies that for an increase in the fraction of Power the Percentage of Power plot is found to be decreasing and the result are verified using LabVIEW

\section{5..Lab View Control System of Vfd Drive}

Lab VIEW is a Integrated programming environment for data collection, graphical analysis and automated testing it uses the $\mathrm{G}$ language, it is entirely dissimilar from other programming languages such as VC, VB and other text-based type program code, Lab VIEW is consists of Virtual Instrument (VI) where we can draw the proposed block diagram in order build the code 


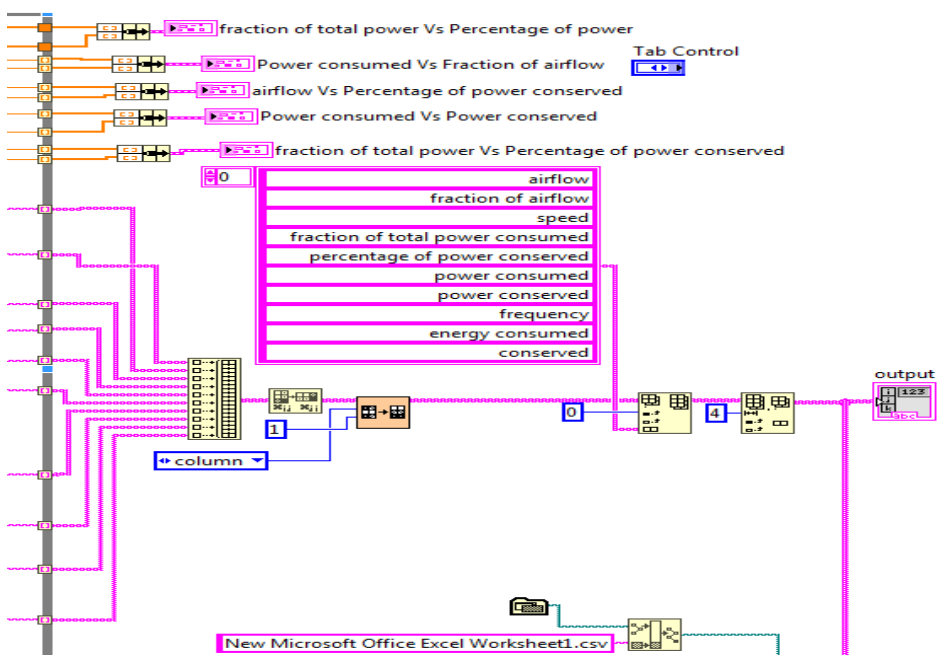

Fig 1.9 Block Diagram of Labview

\section{A. Front Panel of Labview}

The control block diagram of Induced draft Fan could be simulated and developed with help of virtual instrument technology, in the LabVIEW software which is shown in block diagram of control system.document can be used as a template for papers to be published in EAI Core Proceedings. Follow the text for further instructions on text formating, tables, figures, citations and references.

The control panel display consists of some connectors for the dafault datatypes which is uesed for specfic polymorphic function

TF This connector indicates system defines the decimal separator. If the value is TRUE (default), then the decimal separator uses the localized decimal separator. If FALSE, the decimal separator is a period.

TBEL The number can be a scalar number, array or cluster of numbers, array of clusters of numbers, and so on.

width must be numeric. If unwired, the function uses exactly as many digits as are needed to represent the number, with no extra padding.

I16 The precision must be numeric. The function rounds the number of digits after the decimal point of the output string to precision.

F-format string is the resulting fractional string. F-format string can be Inf, -Inf, or NaN if the value you wire to number is infinity or is not a number. The following table shows how the 
values of number, width, and precision affect F-format string. In this table, the underline character ( _ ) represents a space in F-format string.

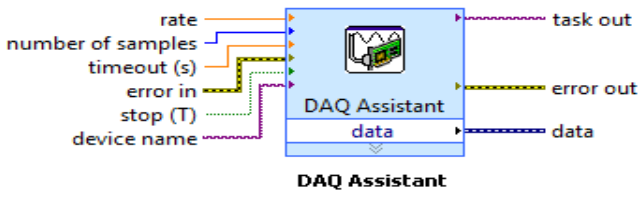

Fig 2.0 Block diagram of DAQ Assistant

The DAQ Assistant is an easy-to-use graphical interface for configuring measurement tasks and channels and for customizing timing, triggering, and scales without programming.

Sort 2D Array: Extracts each row, individually, using index array function, then use equal function. Right click the equal function to set it to either compare elements or compare aggregates (select from comparison mode) to get an array of individual comparisons of corresponding elements or to compare the entire array and output a single boolean.

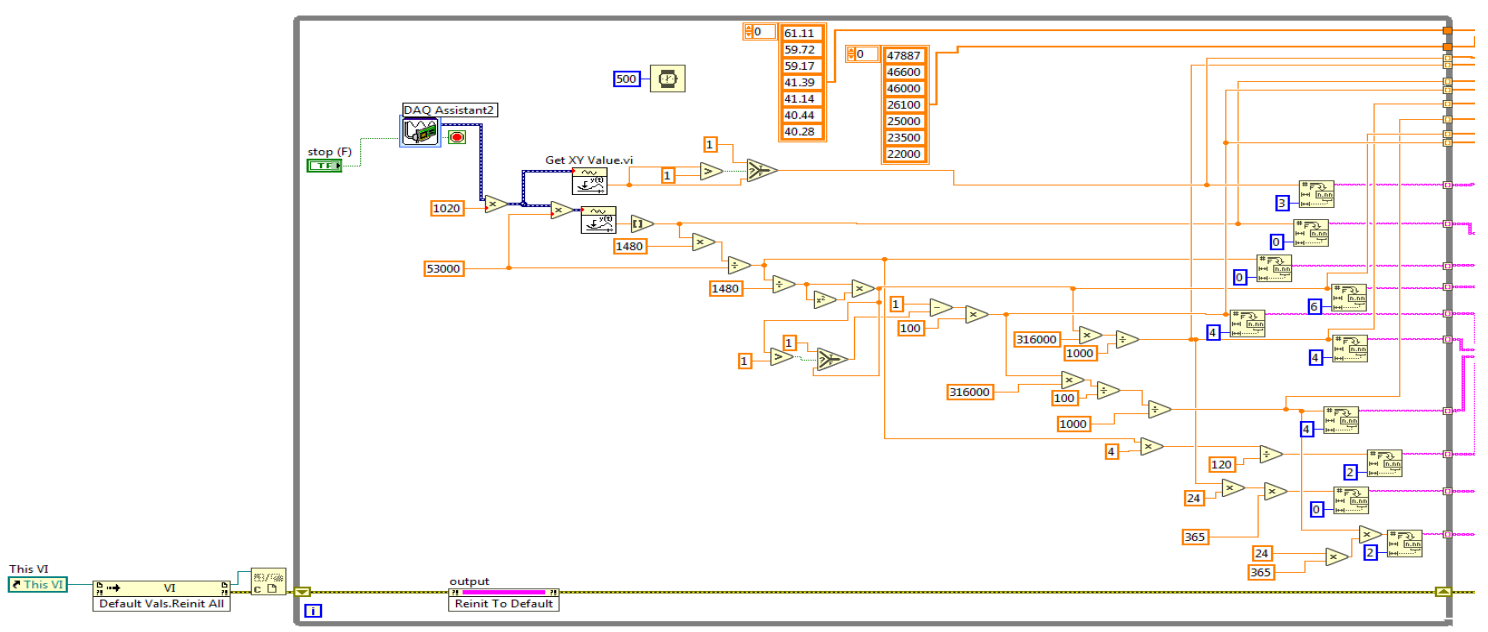

Fig 2.1 Block diagram of VFD Drive in Labview

\section{c) Labview Results}

Fig 2.2 Power Consumed Vs Air flow shows the Power Vs Air flow plot signifies the linear increase in the Pressure when the flow is increased when it is operated using with VFD Drive. This 
plot is verified using LabVIEW and it is much more efficient compared to the operation without VFD

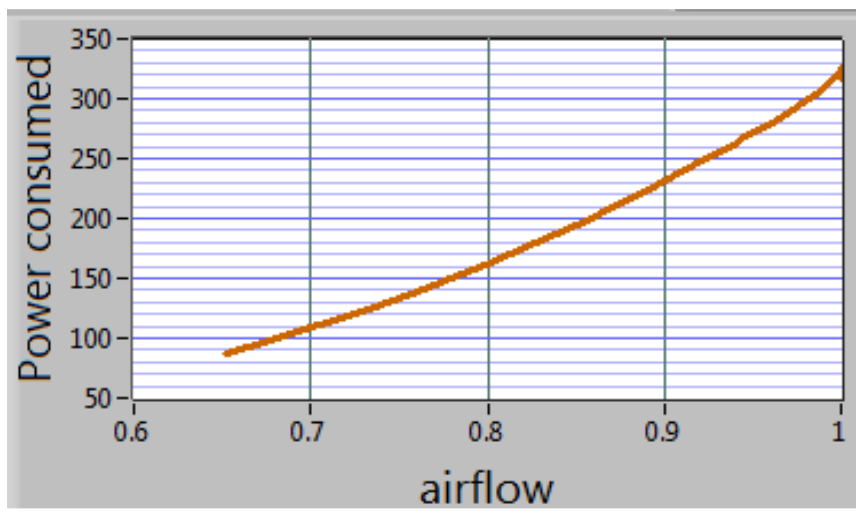

Fig 2.2 Power Consumed Vs Air flow

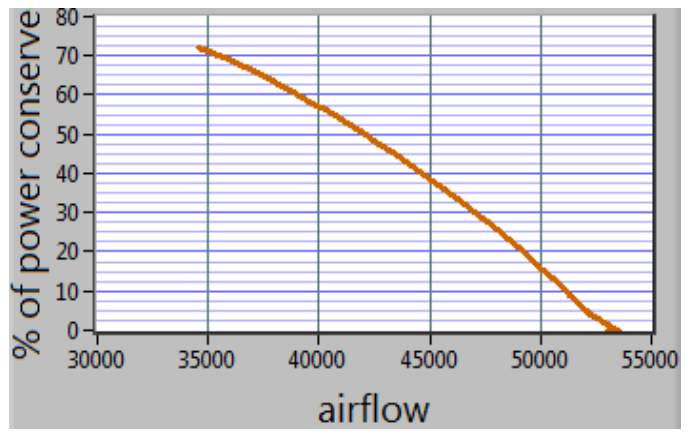

Fig 2.3 Air Flow Vs Percentage of Power Conserved

Fig 2.3 Air Flow Vs Percentage of Power Conserved reprsents the Airflow Vs Percentage of Power plot signifies that for an increase in the percentage of Power the Airflow is found to be decreasing and the results are verified using LabVIEW.This Figure 2.4 Power Consumed Vs Power Conserved shows the plot of Power consumed Vs Power consinies that for maximum airflow the Power Consumed increases and for maximum power consumed the amount of Power Conserved is found to be decreasing thus maximum airflow is not much efficient 


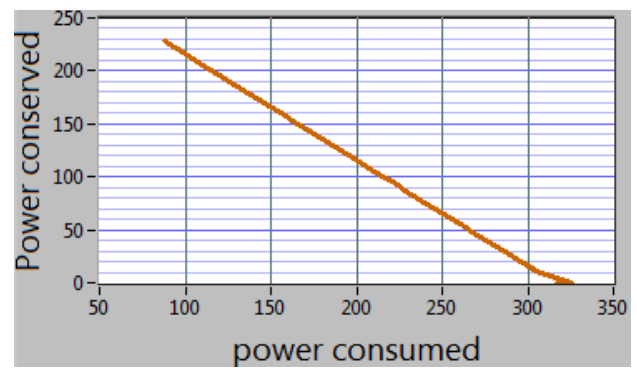

\section{Conclusion}

Fig 2.4 Power Consumed Vs Power Conserved

The above simulation results and discussions are helps to conclude with certain investigation detail report, so that the proposed new methods are reducing the hardware requirement compared to the traditional control system. Obviously it has more compensation in the both hardware and software integration. The main advantage of this innovative approach is cost benefit analysis which could be success by LABVIEW software model because controlling of fan using LABVIEW is almost low cost as compared to DCS technique, Inputs and output data are directly interfacing with the personal computer in order to easiest way of work station This proposed system was studied and analyzed in JSW Steel Power Plant, Salem.

\section{References}

[1] Buzoverya, M.T. and Buzoverya, V.M., "Influence of smelting conditions on the carbon consumption in hot metal production, Stal", 202, no. 2, pp. 13-15.

[2] Voskoboinikov, V.G., Gokhman, Yu.I., and Zhurakovskii, B.L.,"Blast furnace performance with the injection of hot reducing gases (with no air blast), Stal", 1971, no. 4, pp. 303-308.

[3] Pavlov, M.A., Metallurgiyachuguna. Ch. 2. Domennyiprotsess "The Metallurgy of Iron, Vol. 2: The Blast Furnace Process", Moscow: Metallurgizdat, 1949, 6th ed.

[4] Donskov, E.G., Lyalyuk, V.P., and Donskov, D.E., "Understanding the direct reduction of iron in blast furnaces and the Gruner principle", Byul. Chern. Metall., 2013.

[5] Kitaev, B.I., Yaroshenko, Yu.T., and Lazarev, B.L., Teploobmen v domennoipechi "Heat Transfer in Blast Furnaces", Moscow: Metallurgizdat, 1960.

[6] Ramm, A.N., Sovremennyidomennyiprotsess "The Blast Furnace Process Today", Moscow: Meta lurgiya, 1980.

[7] Donskov, E.G. and Lyalyuk, V.P., Upravleniekhodomdomennoiplavki "Blast-Furnace Management", Saarbrucken, Germany: Palmarium Academic, 2013.

[8] Donskov, E.G. and Lyalyuk, V.P., Sokrashenieraskhodaenergoresursov v vyplavkechuguna "Reducing the Energy Consumption in Hot-Metal Production", Saarbrucken, Germany: Palmarium Academic, 2014.

[9] Prime, J.B. Valdes, J.G., "Use of ladder diagram in discrete system of PLC", IEEE Transaction, Vol. PAS-100, pp-143-153, January 1989.

[10] Gregory K. McMillan, Douglas M. Considine (Ed), "Process/Industrial Instruments and Controls Handbook Fifth Edition, McGraw-Hill ”, 1999 ISBN 0-07-012582-1 Section 3 Controllers

[11] Yongheng Zhang, Xia Huang Houshangi, N. Model predictive control via system identification for a hot blast stove. Canadian Conference Electrical and Computer Engineering, 2008, CCECE 2008 
[12] Ogata K., Modern Control Engineering. 5th Edition. Prentice HallPress. 2005

[13] Tomás Andrés FlenM.,FrancoGuidi,Rodrigo Benedetti, Gastón Lefranc,'Modelization and Identification of the Hot Blast Stove's Heating Cycle IEEE LS Member ”, 2011 9th IEEE International Conference on Control and Automation (ICCA) Santiago, Chile, December 19-21, 2011

[14] Yongheng Zhang, Xia Huang Houshangi, "Model predictive control via system identification for a hot blast stove".Canadian Conference Electrical and Computer Engineering, 2008, CCECE 2008.

[15] Paper Entitled "A Laboratory Experiment To Teach Closed-Loop" By Elsa De Klerk, IEEE Transactions On Education, Vol. 47, No. 2, May 2004.

[16] D. Royer, L. Levin, And 0. Legras "A Liquid Level Sensor Using The Absorption Of Guided Acoustic Waves, IEEE Transactions On Ultrasonics, Ferroelectrics, And Frequency Control, Vol. 40, No. 4, July 1993.

[17] Peter M. Chen, "An Automated Feedback System For Computer Organization”, IEEE Transactions On Education, Vol. 47, No. 2, May 2004.

[18] Pyung Hun Chang, "A Systematic Method For Gain Selection Of Robust Pid Control For Nonlinear Plants Of Second-Order Controller Canonical Form”, IEEE Transactions On Control Systems Technology, Vol. 17, No. 2, March 2009.

[19] Vandani Amin Mohammadi Khoshkar, Bidi Mokhtar, Ahmadi Fatemeh,"Energy analysis and evolutionary optimization of boiler blowdown heat recovery in steam power plants" Energy Convers Manage 2015;106:1-9.

[20] Song Chenxi, Li Mingjia, Zhang Fan, He Ya-Ling, Tao Wen-Quan "A data envelopment analysis for energy efficiency of coal-fired power units in China" Energy Convers Manage 2015;102:121-30.

[21] B. G. Pollet, I. Staffel and K. Adamson (2015)"Current energy landscape in the Republic of South Africa, International Journal of Hydrogen Energy",Vol. 40, No. 46, P. 1668516701.

[22] R. Ravinesh, P. Josef, N. Loganathan and R. Devi (2015) "Exploring the role of energy, trade and financial development in explaining economic growth in South Africa: A revisit, Renewable and Sustainable Energy Reviews", Vol. 52, P. 1300-1311.

[23] J. H. Marais, "Analysing DSM opportunities on mine conveyor systems," $\mathrm{PhD}$ thesis, NWU,Potchefstroom, SA, 2007.

[24] C. J. R. Kriel, "Modernising underground compressed air DSM projects to reduce operating costs," M.Eng thesis, NWU, Potchefstroom, SA,2014.

[25] L. E. Zeelie, W. J. Breytenbach and J. H. Marais, "Investigating the possibility of a cost saving intervention on a blast furnace cold blast system," in ICUE, 2016.

[26] Nagaraju, V., Suresh, G., Uthayakumar, C., Jijina, G.O., VLSI Tree-Based Inference Design Applications for Low-Power LearningJournal of Physics: Conference Series, 2021, 1964(6), 062047

[27] Uthayakumar, C., Jijina, G.O., Suresh, G., Nagaraju, V., FPGA Based Approximate Digital VLSI Circuit Validating Focused on Fault Diagnosis, Journal of Physics: Conference Series, 2021, 1964(6), 062079

[28] Jijina, G.O., Mohana Priya, R., Solainayagi, P.” FPGA Realization of Reconfigurable DA-Based Digital FIR Filter Using DRPPG and MCSA Techniques", Lecture Notes in Networks and Systems, 2021, 179 LNNS, pp. 527-544 